\title{
Twenty-Four-Hour Activity Budgets of Mule Deer, Odocoileus hemionus, in the Aspen Parkland of Eastcentral Alberta
}

\author{
Gerald W. KuZYK ${ }^{1,2}$ and Robert J. HudSON ${ }^{1}$ \\ ${ }^{1}$ Department of Renewable Resources, University of Alberta, Edmonton, Alberta T6G 2H1 Canada \\ ${ }^{2}$ Present address: Ministry of Environment, Wildlife Science Section, P.O. Box 9338, Victoria, British Columbia V8W 9M1 \\ Canada; e-mail: Gerald.Kuzyk@gov.bc.ca
}

Kuzyk, Gerald W., and Robert J. Hudson. 2007. Twenty-four-hour activity budgets of Mule Deer, Odocoileus hemionus, in the aspen parkland of eastcentral Alberta. Canadian Field-Naturalist 121(3): 299-302.

We documented seven 24-h activity budgets of two adult Mule Deer (Odocoileus hemionus) does without fawns in the Aspen Parkland of Alberta when the vegetation was green (June, July), maturing (September) and cured (October). They spent about $40 \%$ (mean $=42.3 \%$ ) of each day foraging, somewhat more when vegetation was green $(40-47 \%)$ and maturing $(45 \%)$, and less time in October, when the vegetation was cured (38-39\%). The percentage of time Mule Deer were bedded each day generally equaled or slightly exceeded (33-53\%) that of foraging. Walking was a prevalent activity (3-24\%), especially in autumn and little time was invested in other activities such as social interactions and grooming (1-4\%). There were generally more feeding bouts (10-16/day) than bedding bouts (4-10/day) per day, and feeding bouts were shorter (37-68 minutes) than bedding bouts (69-133 minutes). Mule Deer displayed polycyclic feeding cycles with slight increases in feeding activity near dawn and dusk.

Key Words: Mule Deer, Odocoileus hemionus, activity, foraging, Alberta.

Mule Deer (Odocoileus hemionus) range over much of western North America, yet little is known about their foraging ecology on northern ranges (Kuzyk 2008), especially regarding their daily activities. Documenting how much time Mule Deer spend feeding during different stages of vegetation phenology provides insight into behavioral adaptations in seasonal northern environments. Browsing ruminants normally spend about $50 \%$ each day foraging, with feeding times varying with forage phenology, morphological and physiological characteristics such as mouth shape, gut capacity and food passage rate (du Toit and Yetman 2005). Activity budgets can be used to quantify daily foraging times and other major activities. One difficulty in conducting activity budgets is remaining close enough to a focal animal to accurately quantify activity patterns, especially during darkness. Using tame deer is one way to maintain consistent visual contact with a focal animal for a 24-h period (Collins and Urness 1983) and provides reliable results, as food intake in tame deer is deemed innate (Spalinger et al. 1997). Maintaining visual contact with tame deer also allows daily feeding cycles and duration of feeding bouts to be quantified.

The purpose of this study was to quantify activity budgets of Mule Deer on northern ranges when the vegetation was green (June and July), maturing (September) and cured (October). From allometric considerations (Mysterud 1998; du Toit and Yetman 2005), we predicted that Mule Deer would spend $50 \%$ of their daily activity budget foraging and foraging time would change with forage phenology. We predicted that Mule Deer would spend least time foraging in summer when vegetation was green and the most time in autumn when the vegetation had cured because required selectivity increases search time.

\section{Methods}

Our study animals were two unbred adult Mule Deer does which were hand-reared as fawns. The animals were four and six years old and weighed 59 and $60 \mathrm{~kg}$, respectively, at the beginning of the study. These animals would allow researchers to remain within five meters of them, apparently without disturbing their normal activities. The deer were released into 3-7 hectare fenced enclosures (2.2 m high) in an Aspen Parkland habitat (Strong 1992) at the University of Alberta Ranch $\left(53^{\circ} \mathrm{N}, 111^{\circ} 31^{\prime} \mathrm{W}\right)$ approximately 150 kilometers southeast of Edmonton, Alberta. Each deer was instrumented with a radiocollar (Telonics TGW-3570) and placed in a paddock with two other Mule Deer as part of a larger study (Kuzyk 2008). This study was approved by the University of Alberta Faculty Animal Policy and Welfare Committee (Protocol HUDS 2004-33B), following guidelines of the Canadian Council on Animal Care.

Scan sampling (Altmann 1974) was conducted on focal deer throughout one complete 24 -h period and repeated seven times during the summer and autumn of 2004 and 2005 (Table 1). One Mule Deer (501H) was used for six of the sampling periods and was substituted for another Mule Deer (515K) to compare behaviors at the same season but different years (Table 1). Only one 24-h activity budget was conducted per sampling period. The activity budget was classed into predominant activities and recorded every 10 minutes (Collins and Urness 1983). One observer closely followed 
TABLE 1. Activity budgets (24-h) for one Mule Deer doe $(501 \mathrm{H})$ at the University of Alberta Ranch, Kinsella, Alberta.

\begin{tabular}{|c|c|c|c|c|c|c|c|c|c|}
\hline \multirow[t]{2}{*}{$\overline{\text { Date }}$} & & \multicolumn{2}{|c|}{$\overline{\text { Feeding }}$} & \multicolumn{2}{|c|}{ Bedding } & \multicolumn{2}{|c|}{ Walking } & \multicolumn{2}{|c|}{ Other } \\
\hline & & $\%$ day & $\overline{\mathrm{hrs}}$ & $\%$ day & $\overline{\mathrm{hrs}}$ & $\%$ day & hrs & $\%$ day & hrs \\
\hline 2005 & June 9 & 40.8 & 9.8 & 50.0 & 12 & 6.3 & 1.5 & 2.9 & 0.7 \\
\hline 2004 & July 13 & 41.7 & 10 & 47.9 & 11.5 & 6.3 & 1.5 & 4.2 & 1 \\
\hline 2005 & July 7 & 47.1 & 11.3 & 47.1 & 11.3 & 3.3 & 0.8 & 2.1 & 0.5 \\
\hline 2004 & September 11 & 45 & 10.8 & 32.5 & 7.8 & 21.7 & 5.2 & 0.8 & 0.2 \\
\hline 2005 & September 9 & 44.6 & 10.7 & 38.3 & 9.2 & 15.8 & 3.8 & 1.3 & 0.3 \\
\hline 2004 & October 8 & 38.8 & 9.3 & 36.7 & 8.8 & 23.8 & 5.7 & 0.8 & 0.2 \\
\hline $2005 *$ & October 12 & 38.3 & 9.2 & 52.9 & 12.7 & 7.1 & 1.7 & 2.1 & 0.5 \\
\hline
\end{tabular}

* Note: Different Mule Deer $(515 \mathrm{~K})$.

the deer and used a stopwatch to time predominant activities within a 10-minute bout. An activity had to occur for 5 minutes or longer within a 10-minute time interval to be classed as predominant. Predominant activities were feeding, bedding, walking and other (social interactions, grooming). Feeding was defined as ingesting, chewing or intently searching (smelling plants) for food, while walking was defined as a deer moving without biting vegetation. Ruminating was associated with bedding. Each observer spent between 6 and 10 hours with the Mule Deer and overlapped shifts by approximately 15 minutes to minimize disturbance to the deer. At night, a flashlight was used to monitor the Mule Deer by concentrating the light beam on the posterior portion of the body to minimize disturbance.

Daily patterns of feeding and bedding were determined by the number and duration of bouts that were separated by at least 10 minutes (Pépin et al. 2006). Daily feeding cycles were evaluated by the proportion of time spent feeding each hour over a 24-hr period. The proportion of time spent feeding at dawn and dusk was determined by the mean amount of time spent feeding 1-3 hours before, 1 hour before and 1 hour after and 1-3 hours after sunrise and sunset (Colman et al. 2001). Descriptive analyses of activities are presented due to insufficient sample sizes for statistical comparisons.

\section{Results}

Mule Deer spent about $40 \%$ of each day foraging with slight increases when the vegetation was green and maturing (40-47\%) and less time when the vegetation was cured (38-39\%). Mule Deer spent between $33-53 \%$ of each day bedded (Table 1). Feeding bouts were generally shorter (37-68 $\mathrm{min}$ ) than bedding bouts (69-133 $\mathrm{min})$ and there were more feeding bouts (1016/day) than bedding bouts (4-10/day) per day (Table 2). Feeding cycles were polycyclic (Figure 1) with increased feeding activity near sunrise and sunset (Figure 2).

\section{Discussion}

Our research documented and compared daily foraging activities of Mule Deer on a northern range when the vegetation was at three phenological states, and deer were at successive stages of their annual growth cycle. Our findings did not meet our prediction that Mule Deer would spend less time foraging in summer than in autumn. We assumed abundant forage quantity and quality would account for reduced foraging activity in summer, but early summer is the period when weight gain and appetite are greatest, despite the absence of milk production for fawns. Possibly Mule Deer were being very selective in forage quality in the summer period and spent more time consuming the

TABLE 2. Number and duration (mean min/bout \pm SE) of feeding and bedding bouts for one Mule Deer doe (501H) during 24-h periods at the University of Alberta Ranch, Kinsella, Alberta.

\begin{tabular}{|c|c|c|c|c|c|}
\hline \multirow{2}{*}{\multicolumn{2}{|c|}{ Date }} & \multicolumn{2}{|c|}{ Feeding } & \multicolumn{2}{|c|}{ Bedding } \\
\hline & & Bouts/24-hr & Min/bout & Bouts/24-hr & Min/bout \\
\hline 2005 & 9 June & 16 & $36.9 \pm 5.5$ & 10 & $72.0 \pm 16.5$ \\
\hline 2004 & 13 July & 15 & $40.0 \pm 8.7$ & 10 & $69 \pm 11.6$ \\
\hline 2005 & 7 July & 10 & $68.0 \pm 10.6$ & 6 & $113 \pm 15$ \\
\hline 2004 & 11 September & 12 & $54.2 \pm 11.5$ & 4 & $117.5 \pm 29.3$ \\
\hline 2005 & 9 September & 11 & $58.2 \pm 11.3$ & 5 & $110 \pm 27.6$ \\
\hline 2004 & 8 October & 13 & $43.1 \pm 9.0$ & 4 & $132.5 \pm 41.7$ \\
\hline $2005^{*}$ & 12 October & 12 & $45.8 \pm 9.4$ & 7 & $108.6 \pm 11.0$ \\
\hline
\end{tabular}

* Note: Different Mule Deer (515K). 


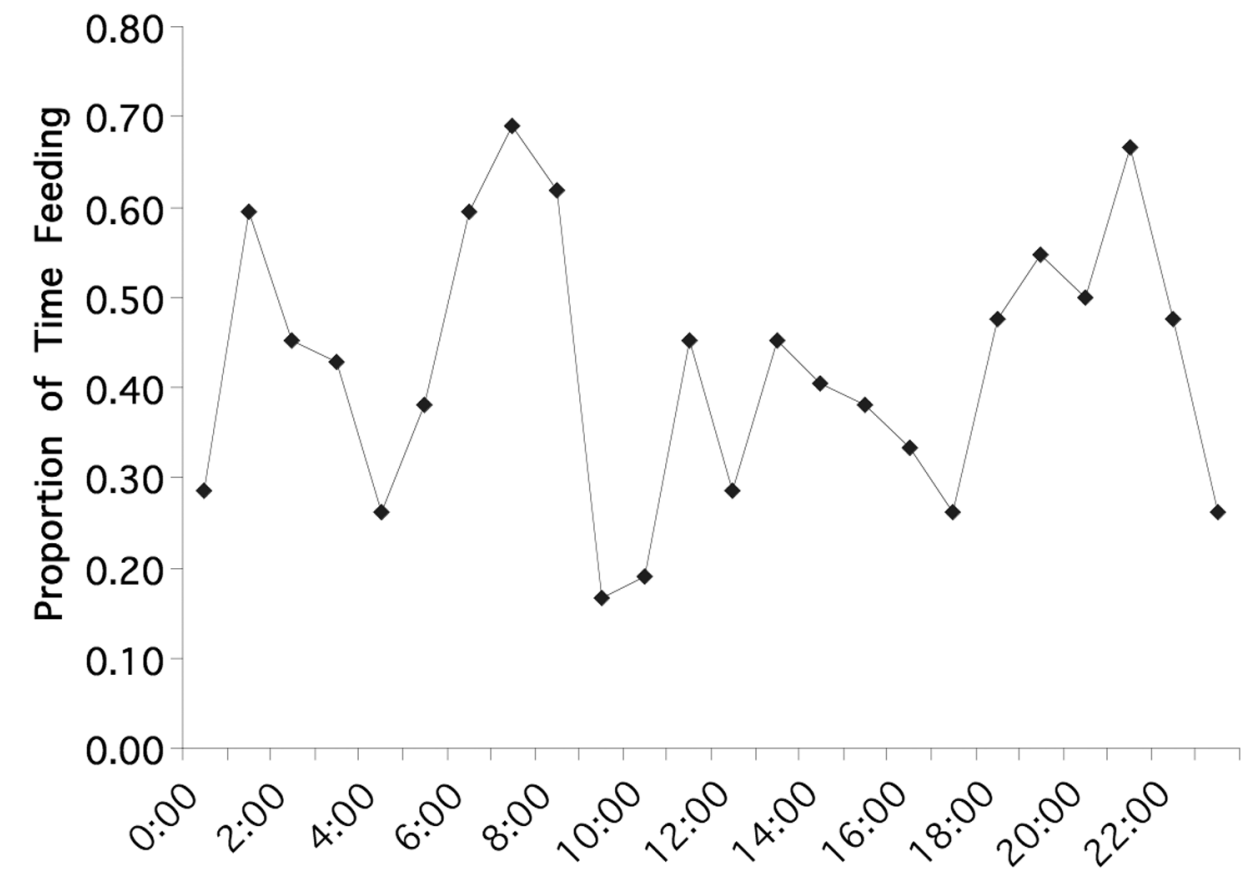

FIGURE 1. Feeding cycles of adult Mule Deer does in the Aspen Parkland of east-central Alberta. Data are averaged and pooled for season (June, July, September, October) and years (2004-2005).

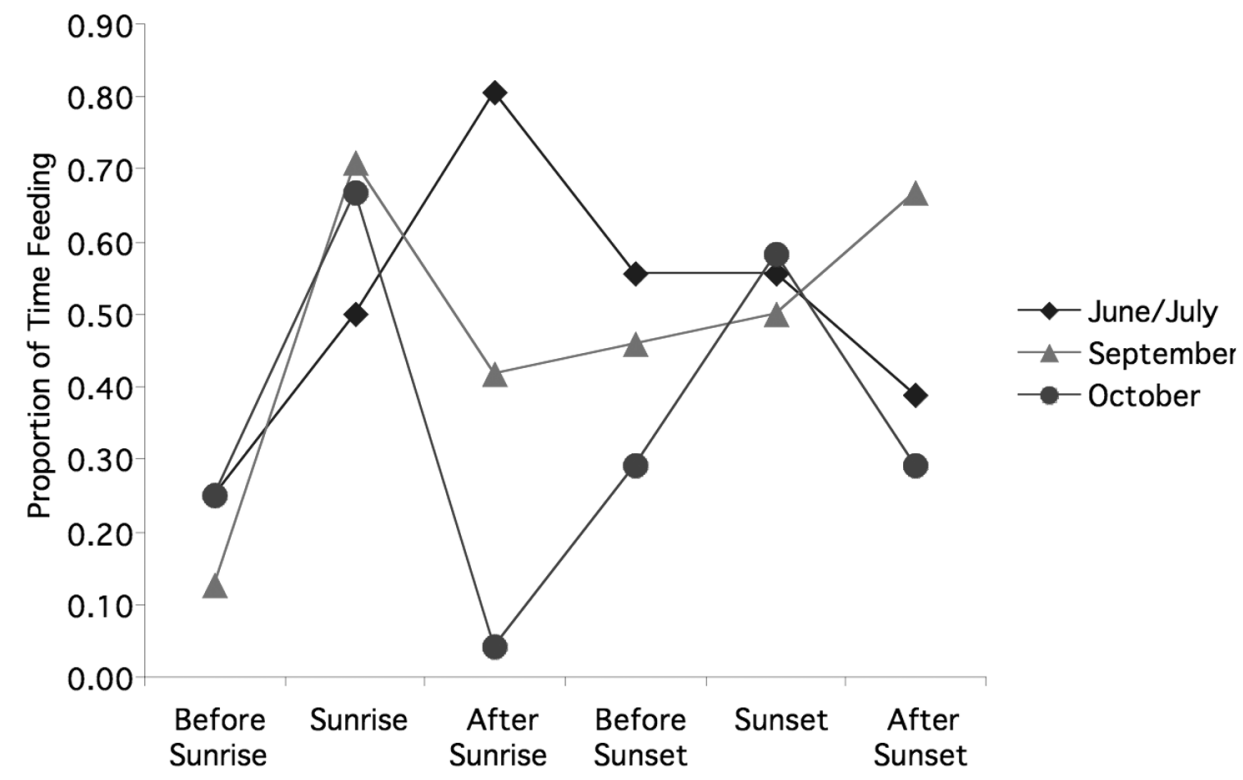

FIGURE 2. Proportion of time a Mule Deer doe spent feeding 1-3 hours before, 1 hour before and after, and 1-3 hours after sunrise and sunset in the Aspen Parkland of east-central Alberta. Data are averaged and pooled for season and years (2004-2005). 
easily digestible forbs when they were readily available. In September, Mule Deer may have increased foraging times as the vegetation started to senesce and deer spent more time searching for green vegetation, especially forbs beneath the grass layer.

Mule Deer spent the least time foraging in October when the vegetation had cured. This may be due to Mule Deer adjusting their bite sizes (Kuzyk and Hudson 2006) to compensate for the lack of green vegetation. Mule Deer on northern ranges have high consumption rates $(\mathrm{g} / \mathrm{min})$ in October and can forage at rates that are near theoretical maximum by feeding on Canadian thistle (Cirsium arvense) (Kuzyk and Hudson 2006). Increased bite sizes in October could lead to a quicker gut fill compared to other seasons.

The percentage of time Mule Deer bedded each day equaled or exceeded that of the time spent foraging. High diurnal temperatures can reduce Mule Deer activity (Hayes and Krausman 1993), especially during midday (Ager et al. 2003), and could account for the difference. Beir and McCullough (1990) found that White-tailed Deer (Odocoileus virginianus) were relatively inactive in summer when feeding on abundant forage. Long bedding bouts may reflect requirements for rumination of coarse forage.

There was variation in behaviors between the two Mule Deer in October in different years. Time spent foraging was almost identical, whereas the time spent bedding contrasted greatly as the individual used in multiple trials $(501 \mathrm{H})$ spent $36.7 \%$ of the day bedding compared to $52.9 \%$ for the other individual $(515 \mathrm{~K})$. Also, $501 \mathrm{H}$ spent substantially more time walking (24\%) than did 515K (7\%), which may be due to individual variations in behaviors.

Mule Deer had polycyclic feeding cycles which has been determined for some other northern ungulates (Colman et al. 2001). The cycles may be driven by rumen fill and time required for digestion (Pérez-Barbería and Gordon 1999), as these Mule Deer experienced little disturbance and few intra-specific interactions (Kuzyk and Hudson 2007). Mule Deer increased feeding activity near sunrise and sunset which is similar to the behavior of White-tailed Deer (Beir and McCullough 1990), as crepuscular activity is a common behavior for small ruminants to reduce predation risk (Pérez-Barbería and Gordon 1999). There appeared to be a more pronounced feeding peak at sunrise, possibly due to rapid daytime heating in summer and fall or increased insect harassment. Additional studies quantifying activity budgets of Mule Deer would help clarify determining factors of daily feeding cycles.

\section{Acknowledgments}

This study was supported by a strategic research grant through the Natural Sciences and Engineering Research Council of Canada and a University of Alber- ta Graduate Research Assistantship. We appreciate the field assistance of P. DeWitt, K. Kuzyk, A. Lockwood, N. Maleki, and S. Vinge and thank B. Irving and staff at the University of Alberta Ranch (Kinsella) for animal handling.

\section{Literature Cited}

Ager, A. A., B. K. Johnson, J. W. Kern, and J. G. Kie. 2003. Daily and seasonal movements and habitat use by female Rocky Mountain elk and mule deer. Journal of Mammalogy 84: 1076-1088.

Altmann, J. 1974. Observational study of behaviour - sampling methods. Behaviour 49: 227-267.

Beir, P., and D. R. McCullough. 1990. Factors influencing white-tailed deer activity patterns and habitat use. Wildlife Monographs 109: 1-51.

Collins, W. B., and P. J. Urness. 1983. Feeding behavior and habitat selection of mule deer and elk on northern Utah summer range. Journal of Wildlife Management 47: 646663

Colman, J. E., C. Pedersen, D. Ø. Hjermann, Ø. Holand, S. R. Moe, and E. Reimers. 2001. Twenty-four-hour feeding and lying patterns of wild reindeer Rangifer tarandus tarandus in summer. Canadian Journal of Zoology 79: 2168-2175.

du Toit, J. T., and C. A. Yetman. 2005. Effects of body size on the diurnal activity budgets of African browsing ruminants. Oecologia 143: 317-325.

Hayes, C. L., and P. R. Krausman. 1993. Nocturnal activity of female desert mule deer. Journal of Wildlife Management 57: 897-904

Kuzyk, G. W. 2008. Carrying capacity of sympatric ungulates in central Alberta. PhD thesis. University of Alberta, Edmonton, Alberta.

Kuzyk, G. W., and R. J. Hudson. 2006. Using $n$-alkane markers to estimate forage intake of mule deer. Canadian Journal of Zoology 84: 1576-1583.

Kuzyk, G. W., and R. J. Hudson. 2007. Animal-unit equivalence of bison, wapiti and mule deer in the aspen parkland of Alberta. Canadian Journal of Zoology 85: 767-773.

Mysterud, A. 1998. The relative roles of body size and feeding type on activity time of temperate ruminants. Oecologia 113: 442-446.

Pépin, D., P. Renaud, B. Dumont, and F. Decuq. 2006. Time budget and 24-h temporal rest-activity patterns of captive red deer hinds. Applied Animal Behaviour Science 101: 339-354.

Pérez-Barbería F. J., and I. J. Gordon. 1999. The relative roles of phylogeny, body size and feeding style on the activity time of temperate ruminants: a reanalysis. Oecologia 120: 193-197

Spalinger, D. E., S. M. Cooper, D. J. Martin, and L. A. Shipley. 1997. Is social learning an important influence on foraging behavior in white-tailed deer? Journal of Wildlife Management 61: 611-621

Strong, W. L. 1992. Ecoregions and ecodistricts of Alberta. Volume 1. Alberta Forestry, Lands, and Wildlife, Land Information Services, Edmonton, Alberta.

Received 5 February 2007

Accepted 16 July 2008 